Article

\title{
Ensuring the Long-Term Sustainability Cooperation with Stakeholders of Sports Organizations in SLOVAKIA
}

\author{
Michal Varmus *, Milan Kubina, Gabriel Koman and Patrik Ferenc \\ Faculty of Management Science and Informatics, University of Zilina, Univerzitna 8215/1, \\ 01026 Zilina, Slovakia; milan.kubina@fri.uniza.sk (M.K.); gabriel.koman@fri.uniza.sk (G.K.); \\ patrik.ferenc@fri.uniza.sk (P.F.) \\ * Correspondence: michal.varmus@fri.uniza.sk; Tel.: +421-41-513-4471
}

Received: 23 April 2018; Accepted: 28 May 2018; Published: 1 June 2018

\begin{abstract}
Organizations, nowadays, operate in highly dynamically-developing environments. This fact also applies to sports organizations, which are looking for various ways to succeed or survive in these environments. There are various solutions available, but from a long-term perspective it is important for sports organizations to think in a complex way. One of the solutions of this issue is to ensure the long-term sustainability and development of these organizations. The aim of this paper is to focus on strategic factors in the management of mutual relationships with stakeholders. The importance of managing cooperation with stakeholders is very high for the achievement of both short-term and long-term objectives. This paper presents, in addition to the results of research aimed at the cooperation of sports organizations and their stakeholders ( 425 respondents participated in the research), solutions to issues currently troubling sports organizations in this field. These issues include the lack of funds for the functioning of the sports organization, as well as the insufficient size of sports organization membership. Sports organizations cannot only reduce the intensity of these issues, but can also eliminate them by utilising selected key factors in the management of mutual relationships with stakeholders.
\end{abstract}

Keywords: management; relationships; sustainability; stakeholder engagement; school; sports clubs; sports organizations

\section{Introduction}

Sports organizations exist in a relatively complex and dynamic environment. There is always a team of people behind the success of an organization - teams of managers and employees of the organization. However, they are not the only ones. The external environment in the form of stakeholders, which either try to help the organization to achieve an objective, or, on the contrary, try to prevent the achievement of a determined objective, also has a large impact on the success of the organization.

Stakeholders can be understood as subjects affecting the organization in the course of its activities, but it shall be added that stakeholders are also affected by the organization and its business activity [1]. In the present era, it is important for individual sports organizations to obtain resources-financial, human, material, etc. Stakeholders are suitable for obtaining these resources, because they are able to bring into the organization not only financial, human, or material resources, but also know-how or other skills. Stakeholders can, therefore, be understood as subjects on which the organization depends in achieving its objectives, and also as subjects who depend on the organization in achieving their objectives [1-3]. This statement is completed by Bowie, who claims that stakeholders represent 
those subjects, without which the organization would not be able to exist [4]. In order for sports organizations to achieve success, it is necessary for them to find the right partners for cooperation. Identification of key stakeholders appears to be a decisive factor for success in this field [5], but it is also important to take into account the cultural environment in which the organization acts [6].

Mutual relationships between sports organizations and their stakeholders can be simplified and streamlined by the correct communication, or otherwise correctly set mutual relationships. However, communication or cooperation with several stakeholders requires the need to manage relationships with them. Management of relationships with stakeholders is one of the key parts of the management of the organization [7-9]. It is not easy for sports organizations to manage these relationships, because they have to satisfy the needs of several stakeholders at the same time and, moreover, they have to think about the satisfaction (fulfilment) of their own needs. This is generally a very complex process and incorrect management of these relationships can result in failure to utilise the full potential of individual relationships. Sports organizations are very specific and it is, therefore, very demanding for managers to maintain and develop within them individual relationships with stakeholders.

Decision-making, as one of the main steps in the management of sports organizations, is also currently strongly affected, both directly and indirectly, by external and internal stakeholders. These impacts can be positive or negative, so these organizations should actively deal with them. Managers in sports organizations need to understand the specifics of the sector in which they act and also the general typology of this sector. Simply said, managers of these organizations face a very difficult task if they wish to utilise the full potential of individual relationships between their organization and stakeholders.

Managers often lack experience with the management of these relationships, which has a negative impact not only on their organization, but also on their stakeholders. We consider the most important factors, which have a significant impact on the success of the functioning of the sports organization, on which managers should focus in the management of the sports organization, whether they be culture, cooperation with stakeholders, or the creation or building of a stable, sustainable core of the sports organization, because all these factors are mutually complementary and interdependent.

\section{Methodology}

Our research consists of a combination of several techniques for obtaining data. Data were primarily obtained by means of a questionnaire survey in which 425 elementary schools in Slovakia participated. The data were collected through a validated survey instrument. The sample size with a $95 \%$ confidence interval and $5 \%$ permissible error required 327 respondents. The survey consisted of questions aimed at the selected issue, and was mainly focused on cooperation with sports organizations in Slovakia. As a sample of sports organizations during the survey, we selected tennis clubs in Slovakia. This was, in particular, to ensure consistency of the data within the sporting sector. Another argument was that, since 2008, the Slovak Tennis Association has been supporting the cooperation of schools and tennis clubs to ensure the sustainable development of these clubs. This survey allowed us to obtain facts, opinions, attitudes, needs, and interests, which can be applied to other sports sectors related to the issue at hand. Secondary data were obtained from available documents published by individual stakeholders. We used a combination of several statistical methods for data processing, namely, we used a combination of methods, such as cluster analysis (Hypothesis 1) and correlation by means of the chi-square test and Cramer's V test (Hypothesis 1 and 2). Mentioned data were processed by IBM SPSS Statistics software (Armonk, NY, USA) and Microsoft Excel (3D Maps) (Redmond, WA, USA). Methods, such as induction, deduction, logic, synthesis, or comparison, were also used for the statistical processing of data by means of said analyses, which provide the general complexity and consistency of the processed results. 


\section{Literature Review}

Nowadays, the sports industry also has a strong impact on the environment. One of the solutions is the application of the sustainability programs of the sports industry [10]. Trendafilova et al. [11] recommend sports organizations, while tackling this issue, to focus on trends. These include, for example, active participation in building social values within the community, but also focus on cooperation with stakeholders, because stakeholders affect everything around us. Culture and development in society have significant impacts on sports organizations, and sports has a significant position in building the local identity and social culture [12]. Many foreign and Slovak authors intensively deal with culture and its impact on society, and vice versa. Sports and sports organizations are gradually becoming a separate object of study, e.g., Girginov [6] and his seven main aspects for the study of sports management, or main aspects of culture for the functioning of sports organizations.

Recent changes in society have also affected the traditional community of sports organizations, which were dependent on volunteers who managed sports clubs and staff. As stated by various authors [13-18], professionalization of the organizational dimension of amateur sports organizations in past years has significantly changed the role of volunteers. Sports organizations moved to the level of more professional or commercial organizations and they approach the management of people accordingly [19]. Organizations gradually moved to the situation of more complex management, but also faced financial limitations with regard to the fulfilment of their strategic objectives [20,21].

The term sustainability of the sports organization is, therefore, receiving more and more attention, as confirmed by McCullough, Pfahl, and Nguyen [22], who point to a growing effort to address sustainability issues in the field of sports. Despite the fact that the conference Sustainable Innovation in Sports is held every year, this field is not sufficiently studied for the sports environment, especially with regard to amateur or junior sports, and the complex understanding of this term is generally absent in the field of sports, whereas, as said by Chard and Mallen [23], sustainability of sports should, nowadays, be the priority of management.

Critical and insufficient tackling and understanding the sustainability of sports organizations can be recently seen in Slovakia, as well as in the whole of Europe, where the collision between the European and American cultures in the issue of sports management occurs, as mentioned by several authors [24-28]. The primary objective, namely, the orientation of the sports organization, especially towards commercial business, thereby providing the financial sustainability of the organization, seems to be problematic. It especially concerns the transfer of the American model and structures of sports organizations into European conditions, such as offering sporting facilities and services as products, especially in the case of multifunctional facilities, which offer their premises to various companies or other sports subjects. However, the substantial part of the sports industry is often neglected in this regard, namely, the building of a complex core of the sports organization, i.e., the community of parents, children, professional, and amateur athletes and fans.

\subsection{Management of Stakeholders in Order to Ensure Sustainability of Sports Organizations}

The solution is offered by cooperating with various stakeholders acting in the sports sector. Many models of management of stakeholders were published throughout $[1-4,29,30]$, which were later also applied to the sports environment. Despite studies by several authors in the past, Friedman, Parent, and Mason pointed out the absence of tools in the management of organizations, which would be based on principles of the theory of stakeholders, while the limitations that influence entities in this environment arise from the requirements of stakeholders. According to Casper et al. [31], these individual limitations can be measured similarly between different stakeholders. As it is possible to measure and evaluate the degree of limitations (for sporting organizations) from stakeholders, it can be said that their main finding is that the theory of stakeholders allows a new view of the management of issues within the organization [32]. This finding indicates the space for further deeper study of this issue in many areas-such as sports. It can, therefore, be generally said that, based on this finding and studies aimed at the examination of relationships of stakeholders to sporting events, management of 
sports clubs, identification of stakeholders in sports, or the authority and legitimacy of stakeholders in sports, it can be established that the theory of stakeholders has, with regard to specifics of the environment, a greater significance in the field of sports than in other business fields [33-41]. Despite the proven social and economic importance of sports organizations, individual studies showed that the issues of stakeholders and the social responsibility of organizations in the field of sports are almost ignored. It must be understood that organizations acting in the field of sports have direct relationships with the community and responsibilities to it. Some such responsibilities are often in conflict with commercial objectives of the organization, but, even so, they cannot be ignored. As stated by Donaldson and Preston [42], an organization is formed by the sum of cooperative and competitive interests, which together form one social internal value of the organization. In order to create maximum value for stakeholders, stakeholders must be defined and understood, corporate policy must be reconciled with requirements of stakeholders, and, finally, proper measures for the management of relationships with stakeholders must be implemented. Even in such narrower aspects it can be claimed, according to Argenti [43], that the main issue is the ambiguity as to who are stakeholders. What are their needs, expectations, or impacts? Authors Post, Preston, and Sachs [44], Freeman [45], and Laplume, Sonpar, and Litz [46] agree that understanding stakeholders requires taking a large number of factors into account, and, at the same time, it must be realized how all identified factors affect the strategy and policy of the organization, competitive position, or creation of the organization's value. According to Jones [47], continuous building of trust is an important factor within social responsibility. This all should lead to the creation of a stable sustainable strategy, in which the organization should perceive the management of stakeholders also from the perspective of stakeholders [48,49]. This is similarly pointed out also by Ansari and Stibbe [50], when they state that sustainability is a complex social process, in which it is necessary for stakeholders not only to mutually cooperate and share information, but also to form partnerships in the field of joint interests.

Politicians and governments are also attempting to tackle the situation. Intervention of government and politics in sports is nothing extraordinary in the world, but this tendency could be significantly felt in Slovakia as late as 2015, when a new act on sport was prepared, which clearly formulated rules for financing sports, as well as rules for the functioning of sports organizations at all levels. Similar activities can be observed in several developed countries, which have various programs for the support of sports, not only with regard to funding, but also with regard to education of officers and coaches. Australia can be mentioned as an example, where, in 1994, the Australian Sports Commission, in cooperation with the Australian Social of Sports Administrators, Confederation of Australian Sports, and state departments for sports and recreation prepared the program of volunteer engagement in sports. The aim of this program was to improve the functioning of non-profit sports organizations by providing a series of publications about the management of sport clubs [51,52]. England is another example, where they identified, in 2003, 30 priority sports based on the ability to achieve the vision of an active and successful sporting nation, which was prepared by the organization covering services and funding of sports, Sport England, previously known as the English Sports Council. The plan contains a guidance of how sports can move from the lowest level to the elite level and what sources will be required for it.

\subsection{Mutual Relationship of Stakeholders in the Field of Sports}

There are numerous links between individual stakeholders in the field of sports. It is important for ensuring the long-term sustainability and success of organizations to ensure correct management of relationships with individual stakeholders [53-58]. The most important stakeholders for sports clubs are other sports clubs, fans, the public, partners/sponsors, and schools. There are relationships between these stakeholders, in which several social-psychological aspects that affect them can be identified. These aspects include pro-social behaviour, aggressive behaviour, cooperation, competition (rivalry), and affiliation. Individual stakeholders and their relationships to a sports club are shown in the Figure 1. 


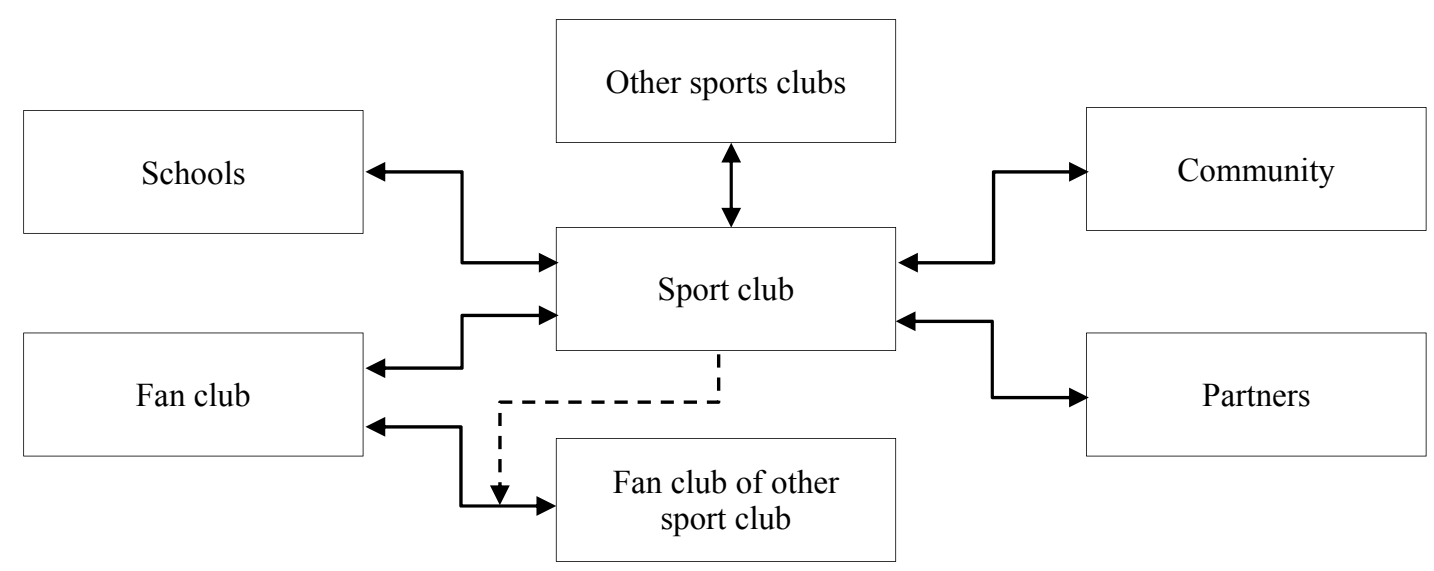

Figure 1. Relationships between the sports club and stakeholders.

\subsubsection{Relationships between the Sports Club and the Public}

With regard to these relationships we can speak of pro-social behaviour between the sports club and the public. This behaviour consists of significantly unilateral activity of the club towards the public without any counter value expected by the club [59]. These activities can, for instance, include supporting non-profit organizations, such as UNICEF, as well as children's hospitals, children's homes, and so on [60-62]. The behaviour within these relationships is very empathic, and these individual activities are often even altruistic.

\subsubsection{Relationships between the Sports Club and Partners}

We can speak of these relationships as cooperative relationships, or also relationships aimed at affiliation. As they can be perceived as business relationships, it is important that cooperating partners avoid perceiving objectives of joint activities differently $[63,64]$. It is important to take care of the fulfilment of objectives and achievement of mutual satisfaction from started cooperation $[65,66]$. Negative aspects affecting these relationships, at most, include competitiveness, achieving success, selfishness, or conceit. In order to develop and manage these relationships effectively it is appropriate to focus the behaviour not only on the mutual empathic and even pro-social behaviour of the sports club and the sponsor, but also on fans who, if they have positive relationships with the club, also positively perceive sponsors and their products $[67,68]$.

\subsubsection{Relationships between Several Sports Clubs}

Behaviour in these relationships is competitive. Rivalry is one of the basic components of sport and belongs to basic aspects of mutual relationships of sports clubs [69]. It can often result in the change from competitive behaviour to aggressive and disrespectful behaviour. This fact can often be seen in sports such as boxing, wrestling, and similar martial arts [70,71], where rivals abuse and insult each other often, even before the match. A solution for coping with these relationships is to control the aggression of athletes by organizers and by their managers.

\subsubsection{Relationships between the Sports Club and the Fan Club}

Behaviour in these relationships is aimed at affiliation, but aggressive behaviour can be also observed. Fans constitute one of the basic stakeholders for organizations active in the field of sport $[63,66]$. Success of a sports club is often conditioned by the support of fans and it is, therefore, important for sports clubs to build the loyalty of their fan base [72]. The loyalty of fans is directly connected with their attitudes and behaviour. Poor results of the sport club can affect the feelings of fans. It is necessary for the long-term sustainability of this relationship to build the feeling of joy and happiness in fans, because these feelings have a positive impact on the building of positive attitudes to the sports club [72]. Despite 
the fact that professional sport could disappear without fans, it is necessary for sports clubs to have their fan clubs under control (in the sense of coping with aggressive behaviour of fans towards other stakeholders). For this control clubs can also use pressure power and standards.

\subsubsection{Relationships between Fan Clubs}

Similarly, as in the case of rivalry between sport clubs, also in these relationships we can speak of competitive and aggressive behaviour. Behaviour between individual fan clubs is given by the nature of the sport in question. It is generally known that this behaviour is shown by fans of dynamic, collective, and popular sports to a larger extent. This behaviour is controlled and regulated by standards and control of aggression, whether by the club or a third party (as mentioned in the previous case).

\subsubsection{Relationships between the Sports Club and Schools}

In this case we can speak of pro-social behaviour. These are very important relationships in the field of sports in any area [73]. Schools represent a very important interested party for clubs and, therefore, clubs often behave in a highly pro-social manner in relationship to them. Clubs are, in this way, trying to gain young athletes [74]. These mutually-empathetic relationships often transform to cooperative relationships, when partnership is formed between the school and the club based on the support of youth sport [75].

Although several authors divide the management principles from the perspective of sports management to management of professional and amateur sports organizations, basic management principles are, in our opinion, very similar. The two most difficult tasks faced by managers of all sports organizations with regard to their sustainability is (a) work with people-as Casper, Pfahl, and McCullough [76] also assert that from the perspective of the sustainability of sports organizations, it is good for sports organizations to develop partnerships with stakeholders within, creating and achieving a common goal (e.g., youth development); and (b) sufficient financial provision.

Financial support of sports organizations is governed in Slovakia by the Act on Sport (Act No. 440/2015 Coll.). A simplified model of funding of sports organizations in Slovakia is shown in Figure 2.

Financial support for sports organizations is, in addition to the mentioned Act, approved on the grounds of an approved criteria of individual national sports associations. A critical factor for funding a sports club is a quantitative criterion, i.e., the number of active sportsmen up to 23 years of age who participate in at least three official events organized by the sports association per year. It can, therefore, be established that the building of the core and, thus, the membership base is necessary for clubs. With regard to that the cooperation with schools seems to be very important; it can even be said that cooperation with schools is crucial with regard to gaining children in clubs, or for the creation and strengthening of the core.

On the grounds of this fact we proceeded with two hypotheses, which would confirm our claim, namely:

Hypothesis 1 (H1). If the sport club cooperates with elementary schools, it has more active athletes.

Hypothesis 2 (H2). There is a dependence between the distance of the school and the sport club and their mutual cooperation in sport-oriented projects.

Verification of these hypotheses was performed by means of the combination of several data processing and statistical techniques-for example, cluster analysis, Pearson chi-square test, Cramer's $\mathrm{V}$, contingency coefficient, comparison of cooperating by tornado chart, geographic view intensity of cooperation, etc. 


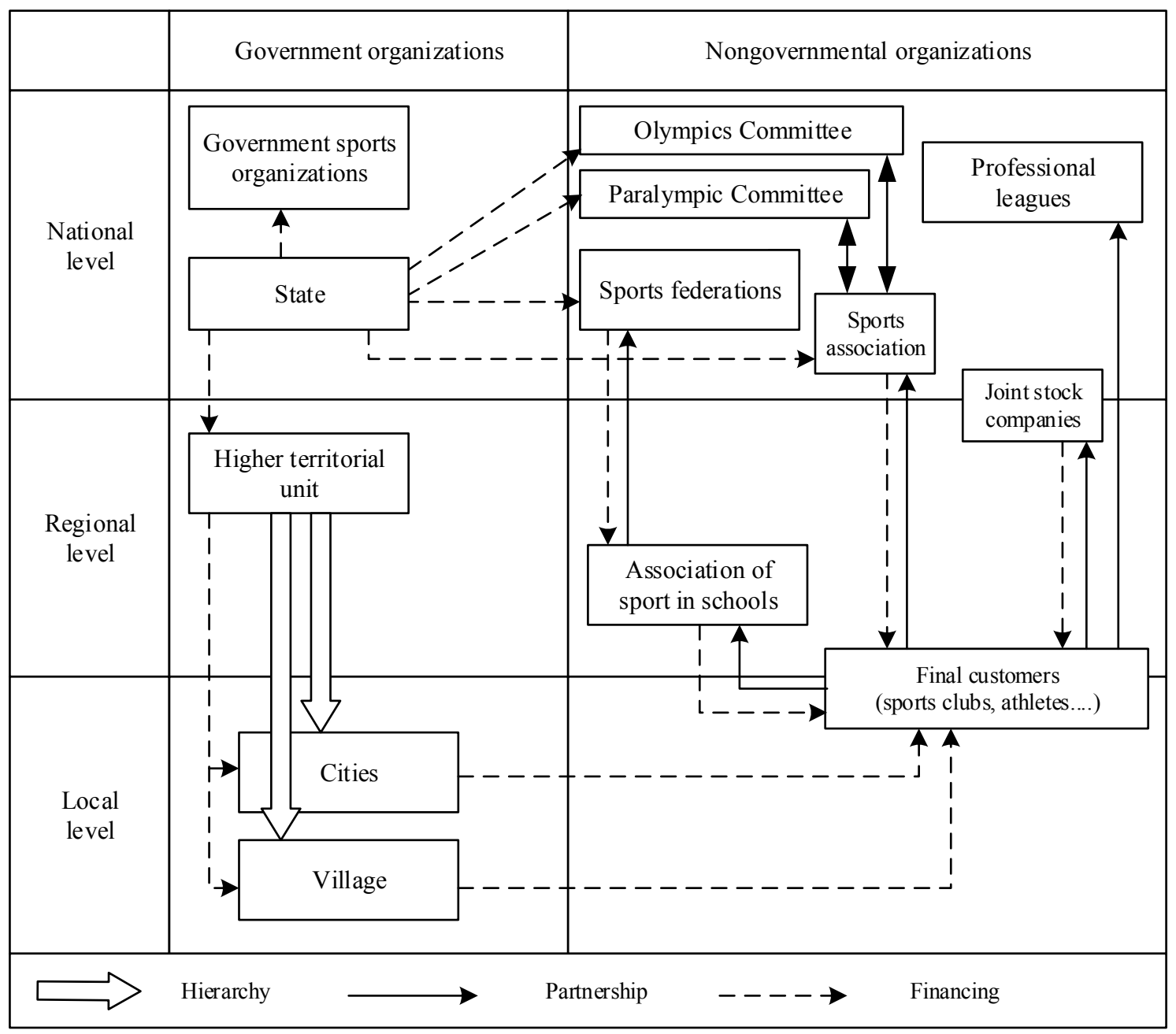

Figure 2. Funding in the field of sport in Slovakia.

\section{Results}

Primary input data were obtained in our research from the questionnaire survey, which was performed from January until May 2014. Elementary schools were the survey target group. There were 2160 elementary schools and 200 tennis clubs registered in Slovakia at the time of the survey. A total of 425 elementary schools participated in the questionnaire survey. The sample size, with a $95 \%$ confidence interval and 5\% permissible error, required 327 respondents and, thus, the sample can be considered representative.

Secondary data were summarised from end-of-year tables published by the Slovak Tennis Association.

The procedure of verification of the first hypothesis H1: If the sports club cooperates with elementary schools, it has more active athletes is as follows.

We understood the active player as a player registered in the national sports association and participating in at least three organized official sports events during one year. The list of clubs together with the number of active players is officially published by the Slovak Tennis Association. We established, on the grounds of the evaluation of data obtained from the questionnaire survey and the analysis of secondary data, that 36 clubs and 36 elementary schools in 30 cities are actively participating in the project. As shown in Figure 3, the cooperation of schools and tennis clubs takes place in various Slovak regions. 


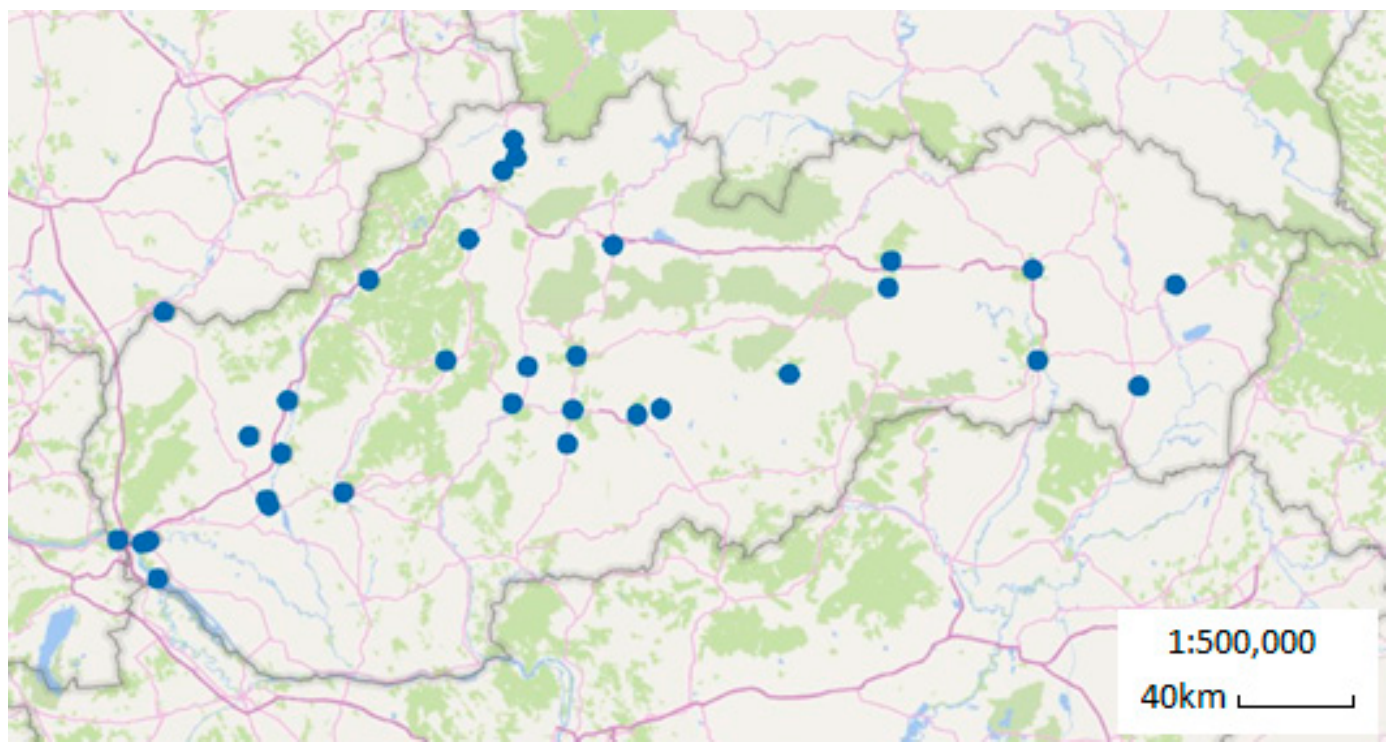

Figure 3. Cities in the Slovak Republic in which there is cooperation between tennis clubs and elementary schools.

Figure 4 shows the intensity of cooperation in individual areas. The intensity of cooperation represents the number of cooperating schools and clubs in individual cities. As can be seen, there are three cooperation clusters formed in Slovakia. One is situated in Western Slovakia, with the highest intensity in the capital Bratislava. The second is situated in the area of Central and Northern Slovakia, with highest intensity in the area of the regional cities Žilina and Banská Bystrica. The third cluster can be observed in the area of Eastern Slovakia, with the highest intensity in the cities Prešov, Poprad, and Košice. It can be established on the grounds of this observation that the cooperation of schools and tennis clubs takes place in Slovakia, especially in larger cities.

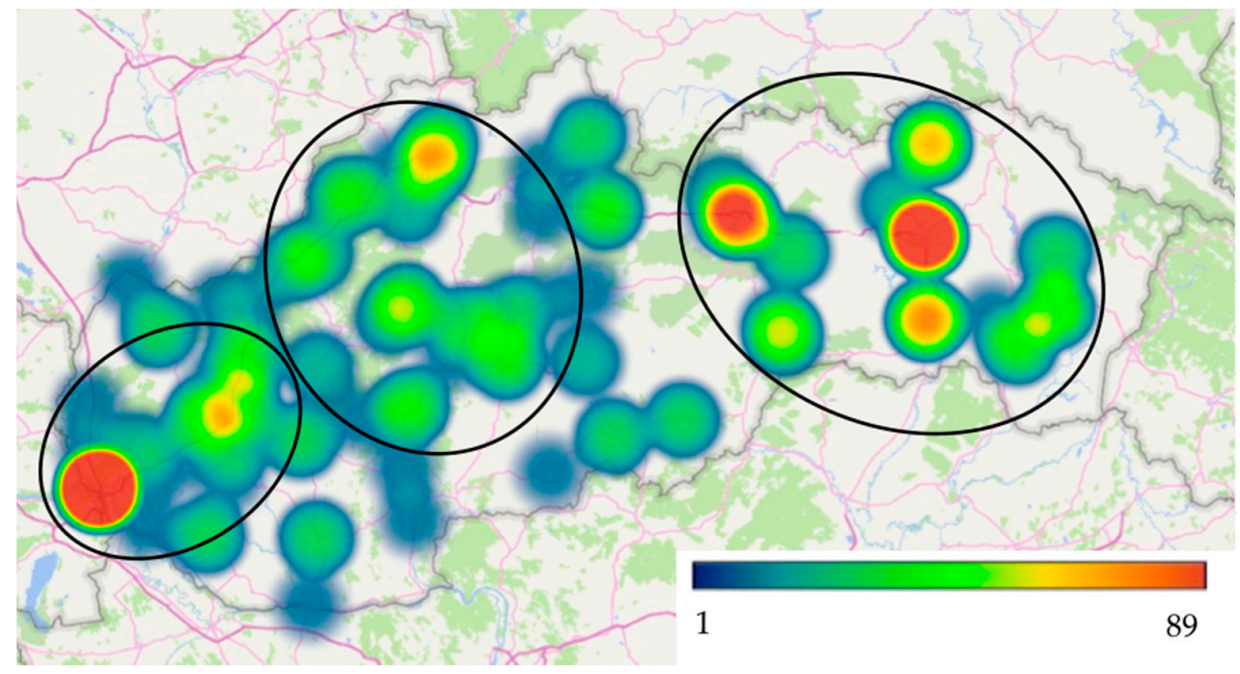

Figure 4. Intensity of cooperation in individual cities in the Slovak Republic.

Figure 5 shows the number of active players up to 23 years of age registered in individual tennis clubs. As can be seen, most players are registered in clubs situated in the cities of Bratislava, Košice, Banská Bystrica, Trnava, and Prešov. A comparison of the number of registered players and the intensity of cooperation shows that cities where a higher intensity of cooperation is observed; there are also more registered players up to 23 years of age in individual tennis clubs. 


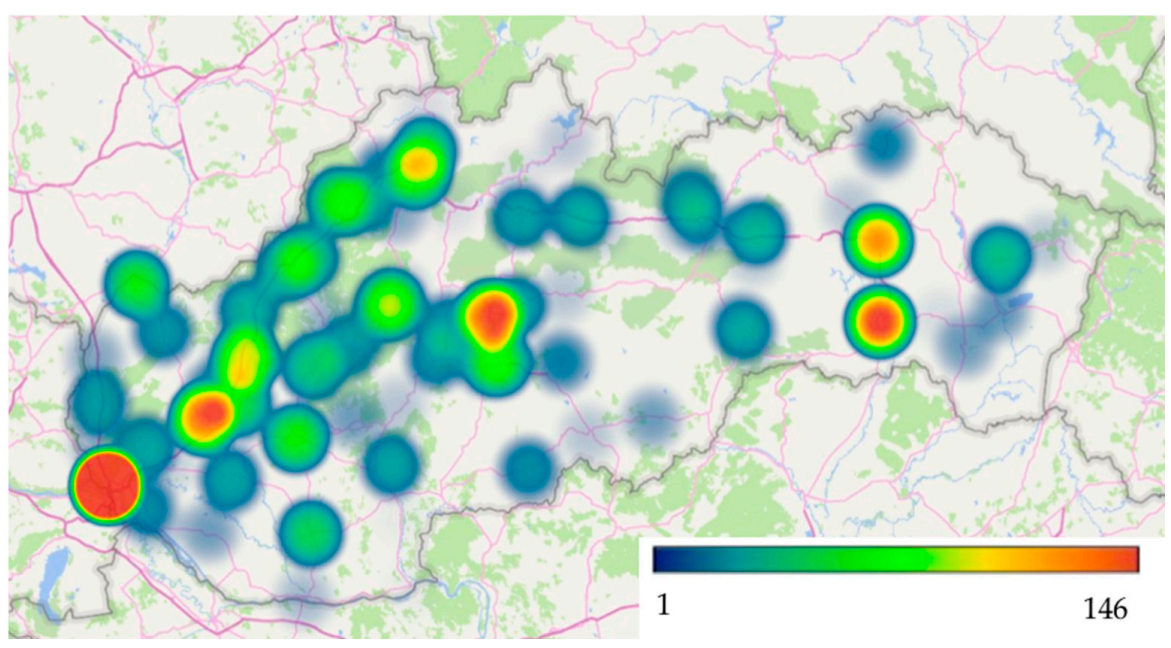

Figure 5. Numbers of active players in individual cities in the Slovak Republic.

This fact is also shown in the following contingency Table 1, which shows that tennis clubs that cooperate with elementary schools have a higher average of active players up to 23 years of age than clubs that do not cooperate with schools.

Table 1. Comparison of clubs with regard to their cooperation with schools.

\begin{tabular}{cccc}
\hline $\begin{array}{c}\text { Collaboration School } \\
\text { and Tennis Club }\end{array}$ & Frequency & $\begin{array}{c}\text { Average Number of Active } \\
\text { Members in Clubs }\end{array}$ \\
\hline \multirow{3}{*}{ Valid } & Yes & 36 & 24.94 \\
& No & 134 & 10.65 \\
& Sum & 170 & 13.68 \\
\hline
\end{tabular}

The number of active members also has, as mentioned above, an impact on the funding of tennis clubs with regard to individual rules for the distribution of funds. Figure 6 shows the impact of results of cooperation with schools and the number of active members on the funding of individual tennis clubs.

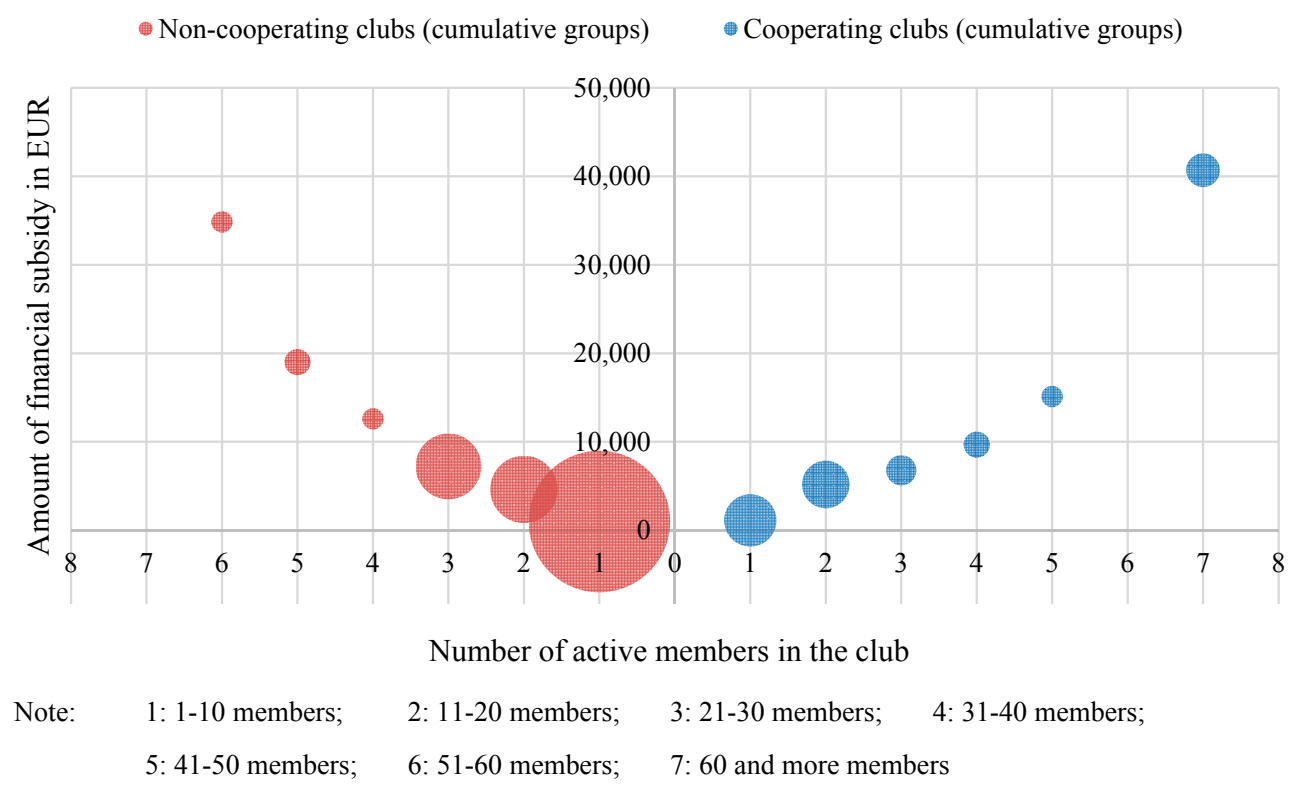

Figure 6. Comparison of cooperating and non-cooperating tennis clubs and their financial allocations. 
The graph shows that tennis clubs in Slovakia, which do not cooperate, have fewer active members and, therefore, obtain mainly smaller allocations. Clubs, which do cooperate, have more members and, thus, higher allocations. This fact is confirmed by the statistical tests, the results of which can be seen in the following Tables 2 and 3.

Table 2. Testing of dependence.

\begin{tabular}{|c|c|c|c|}
\hline & Value & Asymp. Sig. (Two-Sided) & Degrees of Freedom $(d f)$ \\
\hline Pearson Chi-Square & $1924.577^{\mathrm{a}}$ & 0.000 & 330 \\
\hline Number of valid cases & 170 & & \\
\hline$\chi^{2} \mathrm{tab}$ & $394.62 *$ & & \\
\hline$\chi_{\mathrm{cal}}^{2}>\chi^{2} \mathrm{tab}$ & \multicolumn{3}{|c|}{$\mathrm{H} 1$ is accepted and, therefore, dependence exists } \\
\hline
\end{tabular}

a $100.0 \%$ cells have expected count less than 5 . The minimum expected count is $0.01 .{ }^{*} \chi^{2}$ tab for DF value 350 .

Table 3. Calculation of C, V, and Pearson correlation coefficient in SPSS.

\begin{tabular}{ccc}
\hline & Pearson correlation & Value \\
\hline & coefficient & 0.913 \\
\hline Nominal by Nominal & $\begin{array}{c}\text { Cramer's V } \\
\text { Contingency Coefficient }\end{array}$ & 0.869 \\
& Number of valid cases & 170 \\
\hline
\end{tabular}

It can be established on the grounds of the above fact that hypothesis $\mathrm{H} 1$ can be accepted as confirmed. It can, thus, be claimed that tennis clubs which cooperate with elementary schools have more active members and, consequently, higher financial allocations from the tennis association.

Following the previous hypothesis, it can be further examined whether the distance between the sport club (tennis club in this case) and the school has an impact on the mutual cooperation, that is shown in Table 4. It should be mentioned that 203 schools out of 425 schools answered the question whether the school cooperates with a tennis club, and 30 of them did not specify the distance between the school and the closest tennis club.

Table 4. Distance between the school and tennis club vs. cooperation.

\begin{tabular}{ccccc}
\hline & & School Cooperation with a Tennis Club & \multirow{2}{*}{ Sum } \\
\cline { 3 - 4 } & & Yes & No & \\
\hline \multirow{2}{*}{ The distance } & Up to $100 \mathrm{~m}$ & 13 & 10 & 23 \\
between the school & From $100 \mathrm{~m}$ to $500 \mathrm{~m}$ & 6 & 12 & 18 \\
and the nearest & From $500 \mathrm{~m}$ to $1 \mathrm{~km}$ & 5 & 11 & 16 \\
tennis club & From $1 \mathrm{~km}$ to $3 \mathrm{~km}$ & 8 & 24 & 32 \\
& More than $3 \mathrm{~km}$ & 4 & 80 & 84 \\
\hline & Sum & 36 & 137 & 173 \\
\hline
\end{tabular}

We used the testing of dependence by means of Pearson chi-square test (Table 5) to verify the Hypothesis 2 (H2).

The value of contingency coefficient for Table 6 is 0.535 . This value $C$ (contingency coefficient) indicates that the association is relatively strong and, thus, the hypothesis can be considered confirmed.

Even though the testing took place in particular sport clubs it can be established that the distance between the school and the sport club has a significant impact on the cooperation with regard to similar projects in other fields. 
Table 5. Testing of dependence.

\begin{tabular}{ccc}
\hline & Value & Degrees of Freedom $(d f)$ \\
\hline Pearson Chi-Square & 68.264 & 41 \\
Number of valid cases & 173 & \\
$\chi^{2}{ }_{\text {tab }}^{2}$ & 56.94 & \\
$\chi^{2} \chi_{\text {cal }}>\chi_{\text {tab }}$ & H2 is accepted and, therefore, dependence exists \\
\hline
\end{tabular}

Table 6. Calculation of C and V in the SPSS.

\begin{tabular}{ccc}
\hline & & Value \\
\hline \multirow{2}{*}{ Nominal by Nominal } & Cramer's V & 0.634 \\
& Contingency Coefficient & 0.535 \\
\hline & Number of valid cases & 173 \\
\hline
\end{tabular}

\section{Discussion}

Several authors [21-23] state the basic objectives of sports organizations and their differences with regard to culture and traditions. It can be established based on the above findings that certain interference between American and European cultures is currently occurring in Slovakia. Sports organizations in Slovakia differ to a significant extent in their understanding of their mission, or in their setting of primary objectives. These objectives can be divided into three groups:

1. Achievement of profit-commercial purpose;

2. Achievement of sport success—competitive sports; and

3. Achievement of reasonable profit, as well as success-commercial purpose and competitive sports.

Sports organizations must, with regard to their objectives, choose the relevant strategy and determine priorities with regard to the management of stakeholders, and a collision between profit and success can often occur.

Cooperation with stakeholders is a key factor in the field of management of the sports organization as part of long-term sustainability issues. It is obvious that there are many subjects present in the environment of sport that are important for functioning and success of the sports organization, whether they are schools, municipalities, sports associations, media, suppliers, partners, public, agents of players and, finally, players, visitors, or fans. Basically, every sports organization has to communicate with all these subjects, but not everyone realizes or does so. It is, therefore, necessary for staff at all levels of sports organizations to understand the issues of long-term sustainability [77] and take account of this issue in the performance of their work. It is necessary that this issue be incorporated into all levels of the organization and, thus, become part of the structure and policy of sports organizations [78].

Hoye et al. [51] specify stakeholders of sports clubs and their expectations but, in our opinion, they omit two essential subjects, namely, schools and parents. Another significant aspect that is omitted in specialised literature is the division of these stakeholders to two basic groups, namely, stakeholders by means of which the core of the organization is formed and stakeholders forming the core (Figure 7). This division is important, in our opinion, with regard to the management of these groups and the approach to them. However, this does not exclude the fact that these two groups are mutually influencing each other. It should be, primarily, the management of the sports organization that should strive for their interconnection. 


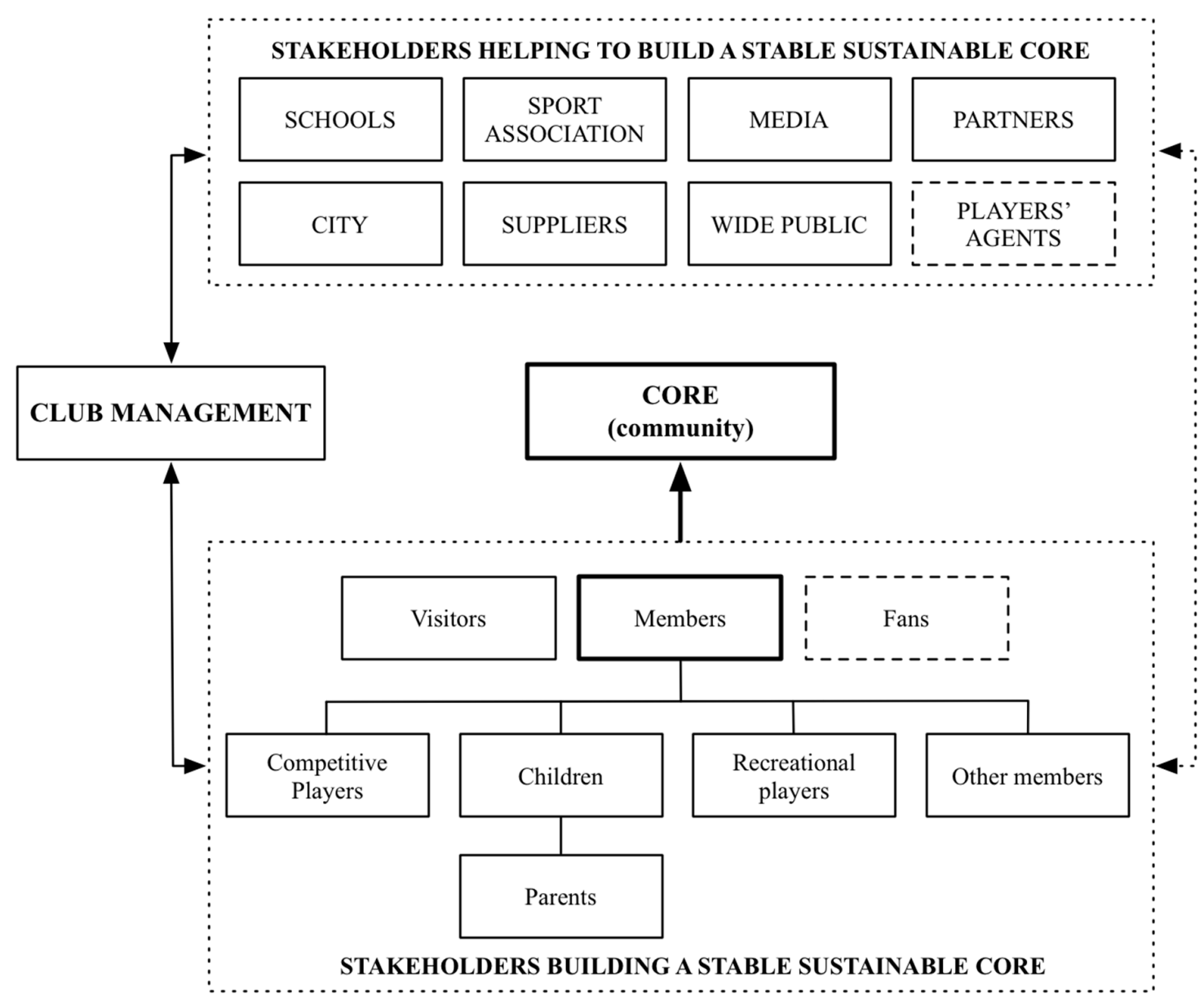

Figure 7. Stakeholders in sports and their division.

Sports associations need wide membership bases and for that they need sports clubs, i.e., these two subjects are closely dependent on each other; on the other hand, sports associations formulate conditions of mutual cooperation. Cities play an important role, especially in providing infrastructure and cooperation with schools under city administration; they also provide media support and influence the public. It can, therefore, be said that the city has a very important position in sports management. Many sports organizations are virtually dependent on cooperation with the city, especially concerning financial allocations, administration, and maintenance of sporting facilities, and assistance in cooperation with other parties. The city of Tampere in Finland can be given as an example, as it has been cooperating with the local sports club and Football Association of Finland since 2011 on the project "Good Feeling and Knowledge Through Sport" [79]. The aim of the project is to organize activities for city inhabitants, especially for children, and to help in coordinating cooperation between schools and local clubs.

There are various examples of cooperation in Slovakia, including direct subsidizing and administration of sporting facilities. However, there is an issue with transparency of the system for the distribution of funds (procedures during which the stipulated subsidy changes on the grounds of subjective decisions of individual authorities). We consider the implementation of a transparent pattern with criteria stipulated in advance to be crucial and, at the same time, motivating and creating synergy.

Schools play, according to MacIntosh and Spence [80], with regard to the provision of programs for the development of sports, a crucial role in the proposition of programs, inputs, and outputs. For instance, there are many internal and external organisational factors, as well as available resources (e.g., money, skills, physical space, and knowledge), which influence how programs are operated [80-82]. The organization has to meet determined conditions for participation in various programs, and they 
often include the membership base. Typical programs or projects include, for instance, the project of the Slovak Tennis Association named "Tennis to Schools". Tennis clubs, elementary schools, and the Slovak Tennis Association understand the importance of these projects, as well as their continuance. Similar projects and understanding of their importance are also common abroad.

The Austrian Federal Ministry for Education, Arts, and Culture and the Austrian Federal Sports Organization agreed on the creation of a program "School and Sport", through which they strive to improve the cooperation between schools and sports clubs. This initiative was designed so as to lead to

- An increase of daily time of physical activity of six- to ten-year olds;

- The concept and formation of physical education oriented around a responsible lifestyle; and

- Mutual complementation and optimisation of opportunities for schools and clubs (creation of synergies).

The article "School and Club in Bewegung and Sport in den Schulen Österreich" states that school sport competitions represent one of the most significant areas of cooperation as to the participation in competitive sports [83]. There has been a successful cooperation in place for a relatively long period of time between national sports federations, sponsors, and school bodies, such as Schülerliga (school league) in football and volleyball, as well as basketball and handball; or school Olympic Games in cooperation with the Austrian Olympic Committee. This cooperation is characterised by

- Joint organization and funding of school sport events from local through provincial to the national level;

- Support of campaigns and their provision;

- Sufficient education, as well as creation of courses for teachers and referees;

- Coaching campaigns when national coaches visit schools;

- Contacts with elite sportsmen when they visit schools or competitions;

- Engagement of national referees in school competitions;

- Opening national competitions for school teams (without the necessity of membership);

- Financial and logistic support from club foundations on school premises; and

- Support and implementation of programs for the processing of results.

The article named "Club Sport Starts in Schools" [84] mentions that the similar cooperative model named "Sport in Schools and Clubs" was established more than 20 years ago in Germany. Karin Agustin, president of the Sports Federation, says that similar partnerships offer the opportunity to inspire students to participate in sports clubs. The cooperation was based on 515 cooperation agreement as part of the project "Sport in Schools and Clubs" for 2013 (by 25 more than in the previous year), whereas 22 of them have been in existence since the project foundation in 1994. A total of 306 elementary schools and 136 secondary schools participated with regard to various sports, mainly football (66), tennis (51), and handball (39). Each such cooperation is donated with the amount of 300 EUR for school on an annual basis, whereas costs are jointly shared by the Sports Federation and the state Rhineland-Palatinate.

Good relationships with suppliers, which can also be in the form of partnerships, are a sign of certain quality and material provision of the functioning of the organization.

Work with media and with partners has a significant effect not only from the perspective of financial coverage, but also from the perspective of increasing the awareness and credibility of the sports organization in the eyes of wider public and, thus, influences a number of potential users of services of the sports organization or future partners.

The most important component of the model is the core and parties forming it. It is often the core that conditions relationships with other stakeholders, but it is also a significant source of funds of the organization, whether it concerns standard membership fees or payments for services or purchasing other products. The core especially means members, then visitors and fans. Members are divided into competitive players, children, recreational players, and other members. 
Competitive players form the group of players that is the bearer of success and image of the sports organization. This is a group of players who try to be successful in competitions and tournaments. As all age categories are represented in this group, it does not include only professional players who receive financial remuneration for their performance, but it concerns a wide array of players with the potential to become professional sportsmen. However, it should be pointed out that it is not the aim of every player to become a professional athlete. They can, for instance, have a personal aim to achieve certain education and sports is a way to obtain it through various programs or scholarships. Sports can also be a life philosophy or certain personal ambition in amateur competitions organized by clubs or associations.

Recreational players or other members are those individuals who perceive sports as part of a healthy lifestyle, or who are active in the organization. This group also has the potential in the field of sponsorship, as enthusiastic athletes can become enthusiastic sponsors, or they can bring their children and, thus, potential competitive players to the club, or they can have a positive impact on other stakeholders.

Children form the group that should have priority in every sports organization. According to Jeon and Casper [85], reasons for the interest of the child (adolescent) for sporting activities are unique, dynamic, influenced by various external factors (friends, family, etc.) and internal factors (age, hobbies, idols, etc.) and, at once, they make up a group with high potential with regard to the future; whether or not they become recreational or competitive players, it is still, therefore, important to focus on this group. This group is interlinked with a number of other stakeholders and also affects the wider public. Sports organizations that have a system of work with youth in place are usually among the successful. The relatively strong position of parents is often neglected, and parents often significantly influence not only children and coaches, but also the management of the organization, and not always only positively. Work with parents should, therefore, have clearly-defined rules, as well as their competencies and the degree of engagement in the organization.

Aforementioned elements in the mentioned model significantly affect the sports organization and its management. Links within the management of the sports organization are shown in Figure 8. As indicated by the figure, the management of stakeholders and of the core of the organization is crucial to ensure financial resources, as well as for the creation of the core and for strengthening mutual links. The strength of these links also depends on the determined objectives of the organization. Conditional links of the functioning of mutual cooperation are marked in red.

Three main resources are possible for the provision of funds necessary for the creation of the core, namely:

- Internal resources, such as membership fees, income from the sale of tickets, and offered services;

- Programs of the state, region, city, or relevant sports association; and

- Partners.

Internal resources depend on the size of the core and set rules, whether it is the membership base, visitors of the organization, or fans. As implied by the text, building the core of the organization forms the substantial base for the functioning of sports organization.

If a sports organization-professional or amateur (volunteer)—wishes to build the core and appropriately manage stakeholders, or to create cooperative clusters, it has to have a clear vision and determined objectives in the context of the strategic approach and, thus, to apply the concept of strategic management emphasised by Hoye et al. [51]. We consider the strategic and innovative approach to be exceptionally important, and as an innovative approach that can be used for forming strategies that can also be used in sports organizations. 


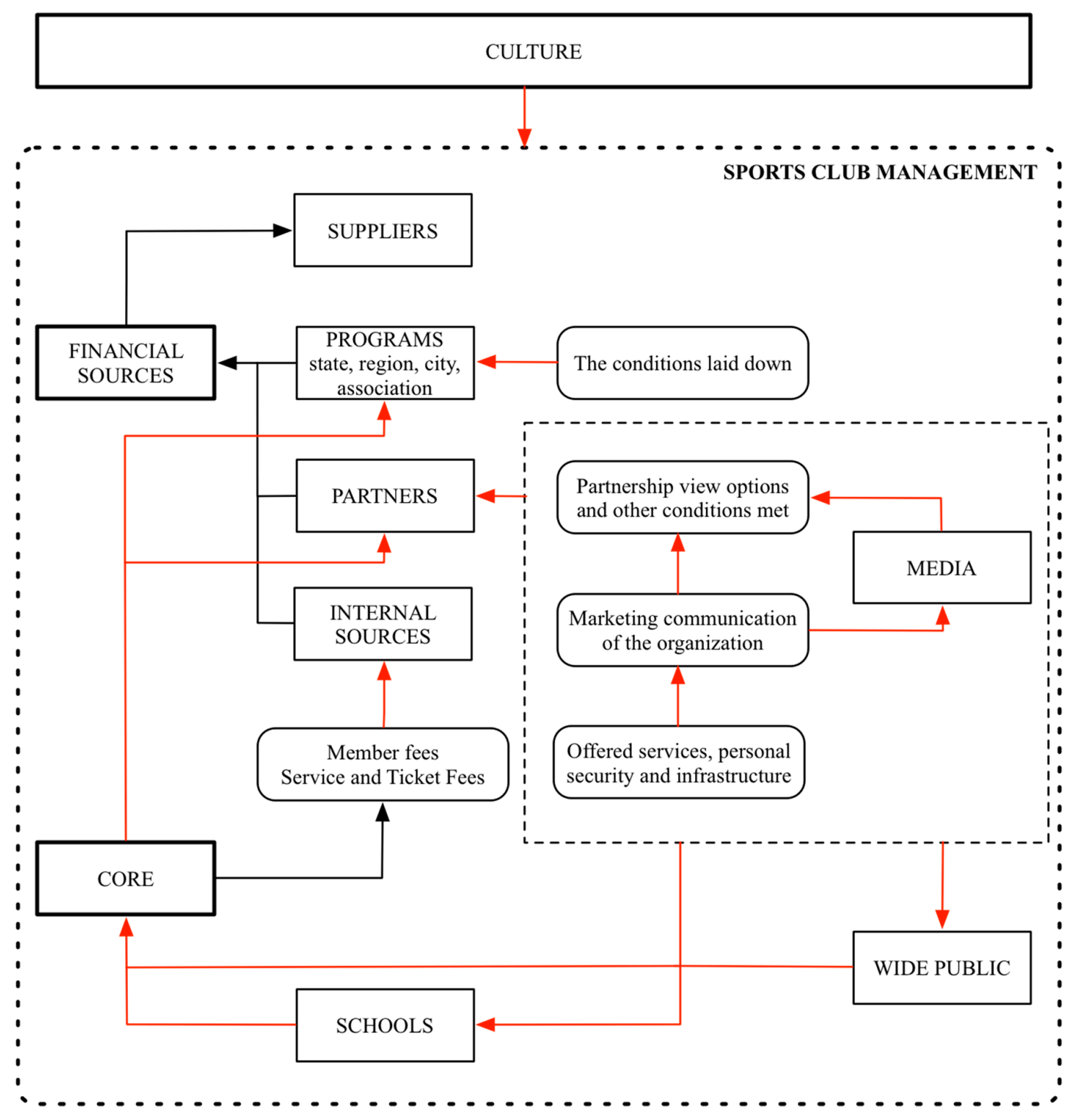

Figure 8. Links in the management of financial flows of a sports organization.

\section{Conclusions}

The aim of this paper was to focus on strategic elements in the management of mutual relationships with stakeholders. Culture, cooperation with stakeholders, and building a stable sustainable core of sports organizations were considered to be strategic elements that will ensure long-term sustainability for sports organizations, because all these factors are mutually complementary and dependent. This claim was confirmed not only by statements from worldwide authors, but also by our own research. The research showed that sports organizations must manage relationships with stakeholders and build a membership base by means of cooperation with schools in order to ensure long-term sustainability.

The main finding confirming our hypothesis is that sports organizations that cooperate with elementary schools have wider membership bases, on the grounds of which they receive higher financial allocations, which are necessary for building the long-term sustainability of the organizations. It can, therefore, be said that key elements of the management of sports organizations include the building of a stable sustainable core (membership base) and the cooperation with stakeholders associated with it. 
The existence of dependence between the distance between sports organizations and schools, and their mutual cooperation, was examined on the grounds of our findings. This hypothesis was formed based on the question of whether the mutual distance between stakeholders forms an obstacle to mutual cooperation. The research resulted in the finding that the distance affects the establishment of potential cooperation. If the distance between the sports club and the school exceeds $3 \mathrm{~km}$, there is only, approximately, a 3\% chance that the partnership relationship will be established between these two organizations.

It is important from a long-term perspective not to forget the significant impact of the factor of culture-which forms an inseparable part of the environment in which organizations operate. This factor is very dynamic and sports organizations have to continuously monitor its development. Changes in this field are often very significant, and early awareness of change in culture can be crucial for sports organizations. One of the most significant changes in the culture of sports is commercialization. Quick reaction to this change, and subsequent adaptation, was one of the main elements in ensuring the sustainability of sports organizations.

The aforementioned implies, as was confirmed several times, that the original claim that the main elements, with regard to ensuring the sustainability of sports organizations, include culture, cooperation with stakeholders, and building a stable sustainable core, is confirmed.

Author Contributions: M.V. and M.K. coordinated the research, P.F. and G.K. analyzed the data, M.V. and P.F. wrote the paper, all authors built the conceptual framework, and all authors contributed to the manuscript preparation.

Acknowledgments: The paper was supported by the project VEGA 1/0617/16-Diagnosis of Specifics and Determinants in Strategic Management of Sporting Organizations.

Conflicts of Interest: The authors declare no conflict of interest.

\section{References}

1. Freeman, R.E.; Reed, D.L. Stockholders and stakeholders: A new perspective on corporate governance. Calif. Manag. Rev. 1983, 25, 93-94. [CrossRef]

2. Rhenman, E. Företagsdemokrati och Företagsorganisation; Thule: Stockholm, Sweden, 1964.

3. Ahlstedt, L.; Jahnukainen, I. Yritysorganisaatio Yhteistoiminnan Ohjausjärjestelmänä; Weilin + Goeoes: Helsinki, Finland, 1971; p. 152. ISBN 9789513504977.

4. Bowie, N. The moral obligations of multinational corporations. In Problems of International Justice; Westview Press: Boulder, CO, USA, 1988; pp. 97-113.

5. Baugh, A. Stakeholder Engagement: The Game Changer for Program Management; Taylor \& Francis Group: Boca Raton, FL, USA, 2015; p. 228. ISBN 978-1-4822-3068-0.

6. Girginov, V. Culture and the Study of Sport Management. Eur. Sport Manag. Q. 2010, 10, 397-417. [CrossRef]

7. Barnett, W.P.; Burgelman, R.A. Evolutionary perspectives on strategy. Strateg. Manag. J. 1996, 17, 5-19. [CrossRef]

8. Burgelman, R.; Grove, A.S. Let chaos reign, then rein in chaos-Repeatedly: Managing strategic dynamics for corporate longevity. Strateg. Manag. J. 2007, 28, 965-979. [CrossRef]

9. Teece, D.J.; Pisano, G.; Shuen, A. Dynamic capabilities and strategic management. Strateg. Manag. J. 1997, 18, 509-533. [CrossRef]

10. McCullough, B.; Kellison, T. Routledge Handbook of Sport and the Environment; Routledge; Taylor \& Francis Group: London, UK, 2018; p. 468. ISBN 9781315619514.

11. Trendafilova, S.; McCullough, B.; Pfahl, M.; Nguyen, S.N.; Casper, J.; Picariello, M. Environmental sustainability in sport: Current state and future trends. Glob. J. Adv. Pure Appl. Sci. 2014, 3, 9-14.

12. Perić, M.; Đurkin, J.; Wise, N. Leveraging Small-Scale Sport Events: Challenges of Organising, Delivering and Managing Sustainable Outcomes in Rural Communities, the Case of Gorski Kotar, Croatia. Sustainability 2016, 8, 1337. [CrossRef]

13. Cuskelly, G.; Tyalor, T.; Hoye, R.; Darcy, S. Volunteer Management Practices and Volunteer Retention: A Human Resource Management Approach. Sport Manag. Rev. 2006, 9, 141-163. [CrossRef]

14. Kikulis, L.M.; Slack, T.; Hinings, B. Does decision making make a difference? Patterns of change within Canadian national sport organizations. J. Sport Manag. 1995, 9, 273-299. [CrossRef] 
15. Kikulis, L.M.; Slack, T.; Hinings, B. Toward an understanding of the role of agency and choice in the changing structure of Canada's national sport organizations. J. Sport Manag. 1995, 9, 135-152. [CrossRef]

16. Slack, T. The bureaucratization of a voluntary sport organization. Int. Rev. Sociol. Sport 1985, 20, 145-165. [CrossRef]

17. Slack, T.; Hinings, B. Understanding change in national sport organizations: An integration of theoretical perspectives. J. Sport Manag. 1992, 6, 114-132. [CrossRef]

18. Thibault, L.; Slack, T.; Hinings, B. Professionalism, structures and systems: The impact of professional staff on voluntary sport organizations. Int. Rev. Sociol. Sport 1991, 26, 83-97. [CrossRef]

19. Chelladurai, P. Human Resource Management in Sport and Recreation, 2nd ed.; Human Kinetics: Champaign, IL, USA, 2006; p. 341. ISBN 9780736055888.

20. Sharpe, E.K. Its not fun anymore: A case of organizing a contemporary grassroots recreation association. Soc. Leis. 2003, 26, 431-452. [CrossRef]

21. Auld, C. Professionalisation of Australian sport: The effects on organisational decision making. Eur. J. Sport Manag. 1997, 4, 17-39.

22. McCullough, B.; Pfahl, M.; Nguyen, S. The green waves of environmental sustainability in sport. Sport Soc. 2015, 19, 1040-1065. [CrossRef]

23. Chard, C.; Mallen, C. Renewable Energy Initiatives at Canadian Sport Stadiums: A Content Analysis of Web-Site Communications. Sustainability 2013, 5, 5119-5134. [CrossRef]

24. Sloane, P.J. The economics of professional football: The football club as a utility maximizer. Scott. J. Polit. Econ. 1971, 121-145. [CrossRef]

25. Cairns, J.; Jennett, N.; Sloane, P. The economics of professional team sports: A survey of theory and evidence. J. Econ. Stud. 1985, 13, 3-80. [CrossRef]

26. Kesenne, S. Player market regulation and competitive balance in a win maximizing scenario. In Competition Policy in Professional Sports: Europa after the Bosman Case; Kesenne, S., Ed.; Standard Editions: Antwerp, Belgium, 1999; pp. 154-196. ISBN 9034111601.

27. Primault, D.; Rouger, A. How relevant is North American experience for professional team sports in Europe. In Competition Policy in Professional Sports: Europa after the Bosman Case; Kesenne, S., Ed.; Standard Editions: Antwerp, Belgium, 1999; pp. 154-196. ISBN 9034111601.

28. Bourg, J.F. Professional Team Sports in Europe: Which Economic Model? In International Sports Economics Comparisons; Fort, R., Fizel, J., Eds.; Praeger Publisher: Westport, CT, USA, 2004; ISBN 0-275-98032-4.

29. Portman, H. MSP: Stakeholder Management, a Refresh. Available online: https://hennyportman.wordpress. com/2014/11/21/msp-stakeholder-management-a-refresh/ (accessed on 12 November 2017).

30. Morphy, T. Stakeholder: Definition-What Is a Stakeholder? Available online: https:/ /www.stakeholdermap. com/stakeholder-definition.html (accessed on 1 September 2017).

31. Casper, J.M.; Bocarro, J.N.; Kanters, M.A.; Floyd, M.F. Measurement Properties of Constraints to Sport Participation: A Psychometric Examination with Adolescents. Leis. Sci. 2011, 33, 127-146. [CrossRef]

32. Friedman, M.T.; Parent, M.M.; Mason, D.S. Building a framework for issues management in sport through stakeholder theory. Eur. Sport Manag. Q. 2004, 4, 170-190. [CrossRef]

33. Putler, D.S.; Wolfe, R.A. Perceptions of intercollegiate athletic programs: Priorities and tradeoffs. Sociol. Sport J. 1999, 16, 301-325. [CrossRef]

34. Trail, G.; Chelladurai, P. Perceptions of goals and processes of intercollegiate athletics: A case study. J. Sport Manag. 2000, 14, 154-178. [CrossRef]

35. Morgan, M. Optimizing the structure of elite competitions in professional sport-Lessons from rugby union. Manag. Leis. 2002, 7, 41-60. [CrossRef]

36. Wolfe, R.A.; Putler, D.S. How tight are the ties that bind stakeholder groups? Organ. Sci. 2002, 13, 64-80. [CrossRef]

37. Friedman, M.T.; Mason, D.S. A stakeholder approach to understanding economic decision making: Public subsidies for professional sport facilities. Econ. Dev. Q. 2004, 18, 236-254. [CrossRef]

38. Parent, M.M.; Deephouse, D.L. A case study of stakeholder identification and prioritization by managers. J. Bus. Ethics 2007, 75, 1-23. [CrossRef]

39. Morrow, S.; Idle, C. Understanding change in professional road cycling. Eur. Sport Manag. Q. 2008, 8, 315-336. [CrossRef] 
40. Senaux, B. A stakeholder approach to football club governance. Int. J. Sport Manag. Mark. 2008, 4, 4-17. [CrossRef]

41. Leopkey, B.; Parent, M.M. Risk management issues in large-scale sporting events: A stakeholder perspective. Eur. Sport Manag. Q. 2009, 9, 187-208. [CrossRef]

42. Donaldson, T.; Preston, L.E. The stakeholder theory of the corporation: Concepts, evidence and implications. Acad. Manag. Rev. 1995, 20, 63-91. [CrossRef]

43. Argenti, J. Stakeholders: The case against. Long Range Plan. 1997, 30, 442-445. [CrossRef]

44. Post, J.; Preston, L.; Sachs, S. Managing the extended enterprise: The new stakeholder view. Calif. Manag. Rev. 2002, 45, 6-28. [CrossRef]

45. Freeman, R.E. The Wal-Mart effect and business, ethics and society. Acad. Manag. Perspect. 2006, $20,37-41$. [CrossRef]

46. Laplume, A.O.; Sonpar, K.; Litz, R.A. Stakeholder theory: Reviewing a theory that moves us. J. Manag. 2008, 34, 1152-1189. [CrossRef]

47. Jones, T.M. Instrumental stakeholder theory: A synthesis of ethics and economics. Acad. Manag. Rev. 1995, 20, 404-437. [CrossRef]

48. Frooman, J. Stakeholder influence strategies. Acad. Manag. Rev. 1999, 24, 191-205. [CrossRef]

49. Friedman, A.L.; Miles, S.V. Developing stakeholder theory. J. Manag. Stud. 2002, 39, 1-22. [CrossRef]

50. Ansari, W.; Stibbe, A. Public Health and the Environment: What Skills for Sustainability Literacy-And Why? Sustainability 2009, 1, 425-440. [CrossRef]

51. Hoye, R.; Smith, A.C.T.; Nicholson, M.; Stewart, B.; Westerbeek, H. Sport Management. Principles and Applications; Routledge: London, UK, 2012; ISBN 978-0-415-50070-8.

52. Productivity Commission. Contribute of the Not-for-Profit Sector; Commonwealth of Australia: Canbera, Australia, 2010; p. 792. ISBN 978-1-74037-304-3.

53. Freeman, R.E. Strategic Management: A Stakeholder Approach, 1st ed.; Pitman: Boston, MA, USA, $1984 ;$ p. 275. ISBN 978-0273019138.

54. Clarkson, M.E. A Stakeholder framework for analyzing and evaluating corporate social performance. Acad. Manag. Rev. 1995, 20, 92-117. [CrossRef]

55. Jawahar, I.M.; McLaughlin, G.L. Toward a descriptive stakeholder theory: An organizational life cycle approach. Acad. Manag. Rev. 2001, 26, 397-414. [CrossRef]

56. Kochan, T.A.; Rubinstein, S.A. Toward a stakeholder theory of the firm: The Saturn partnership. Organ. Sci. 2000, 1, 367-382. [CrossRef]

57. Mitchell, R.; Agle, B.; Wood, D. Toward a Theory of Stakeholder Identification and Salience: Defining the Principle of Who and What Really Counts. Acad. Manag. Rev. 1997, 22, 853-886. [CrossRef]

58. Savage, G.T.; Nix, T.W.; Whitehead, C.J.; Blair, J.D. Strategies for assessing and managing stakeholders. Acad. Manag. Exec. 1991, 5, 61-75. [CrossRef]

59. Misener, K.E.; Doherty, A. Connecting the community through sport club partnerships. Int. J. Sport Policy Polit. 2012, 4, 243-255. [CrossRef]

60. Okayasu, I.; Kawahara, Y.; Nogawa, H. The relationship between community sport clubs and social capital in Japan: A comparative study between the comprehensive community sport clubs and the traditional community sports clubs. Int. Rev. Sociol. Sport 2010, 45, 163-186. [CrossRef]

61. Basketball Stars Visit UNICEF. Available online: https://www.unicef.org/nutrition/haiti_58925.html (accessed on 6 March 2018).

62. Lang, M.; Hartill, M. Safeguarding, Child Protection and Abuse in Sport, 1st ed.; Taylor \& Francis Group: London, UK, 2014; p. 234. ISBN 978-0415829793.

63. Nufer, G.; Bühler, A. The Importance of mutual beneficial Relationships in the Sponsorship Dyad. In Reutlingen Working Papers on Marketing \& Management; ESB Business School: Reutlingen, Germany, 2009; pp. 1-17.

64. Bühler, A.; Nufer, G. Relationship Marketing in Sports; Routledge: London, UK, 2012; p. 208. ISBN 9781136436154.

65. Dionísio, P.; Leal, C.; Moutinho, L. Fandom affiliation and tribal behaviour: A sports marketing application. Qual. Mark. Res. Int. J. 2008, 11, 17-39. [CrossRef]

66. Nufer, G.; Bühler, A. Relevant factors for successful relationships between professional sporting organisations and their sponsors. J. Phys. Educ. Sports Manag. 2011, 2, 26-31. 
67. Johnston, M.; Paulsen, N. The influence of club and sponsor images and club-sponsor congruence in the Australian Football League. Int. J. Sport Manag. Mark. 2011, 9, 29-53. [CrossRef]

68. Smith, A.; Graetz, B.; Westerbeek, H. Sport sponsorship, team support and purchase intentions. J. Mark. Commun. 2008, 14, 387-404. [CrossRef]

69. Hoye, R.; Smith, A.; Nicholson, M.; Stewart, B. Sport Management: Principles and Applications, 4th ed.; Routledge: Abingdon, UK, 2015; p. 383. ISBN 9781317557784.

70. Endresen, I.M.; Olweus, D. Participation in power sports and antisocial involvement in preadolescent and adolescent boys. J. Child Psychol. Psychiatry 2005, 46, 468-478. [CrossRef] [PubMed]

71. Parkinson, A. Anger and Athletics: The Association between Sports and Aggression. Available online: http:/ / newsletter.blogs.wesleyan.edu/files/2011/12/parkinson.pdf (accessed on 6 March 2018).

72. Pan, S.; Wu, H.; Morrison, A.; Huang, M.; Huang, W. The Relationships among Leisure Involvement, Organizational Commitment and Well-Being: Viewpoints from Sport Fans in Asia. Sustainability 2018, 10, 740. [CrossRef]

73. Nicholson, M.; Hoye, R. Sport and Social Capital; Routledge: London, UK, 2008; p. 390. ISBN 9781136365034.

74. Eime, R.M.; Payne, W.R. Linking participants in school-based sport programs to community clubs. J. Sci. Med. Sport 2008, 12, 293-299. [CrossRef] [PubMed]

75. De Knop, P.; Engström, L.M.; Skirstad, B.; Weiss, M.R. Worldwide Trends in Youth Sport; Human Kinetics: Champaign, IL, USA, 1996; pp. 276-281. ISBN 978-0873227292.

76. Casper, J.M.; Pfahl, M.E.; McCullough, B. Intercollegiate sport and the environment: Examining fan engagement based on athletics department sustainability efforts. J. Issues Intercoll. Athl. 2014, 2014, 65-91.

77. Pfahl, M.; Casper, J.; Trendafilova, S.; McCullough, B.; Nguyen, S. Crossing Boundaries. Commun. Sport 2014, 3, 27-56. [CrossRef]

78. Casper, J.; Pfahl, M. Sport Management and the Natural Environment; Routledge: London, UK, 2015 ; p. 286. ISBN 978-0-415-71540-9.

79. Hallmann, K.; Petry, K. Comparative Sport Development. System, Participation and Public Policy; Springer: New York, NY, USA, 2013; p. 355. ISBN 978-1-4614-8904-7.

80. MacIntosh, E.; Spence, K. An exploration of stakeholder values. In search of common ground within an international sport and development initiative. Sport Manag. Rev. 2012, 15, 404-415. [CrossRef]

81. Coalter, F. The politics of sport-for-development: Limited focus programmes and broad gauge problems? Int. Rev. Sociol. Sport 2010, 45, 295-314. [CrossRef]

82. Kidd, B. A new social movement: Sport for development and peace. Sport Soc. 2008, 11, 370-380. [CrossRef]

83. School and Club in Bewegung \& Sport in den Schulen Österreichs. Available online: http://www.bewegung. ac.at/index.php?id=105 (accessed on 12 January 2018).

84. Club Sport Starts as School in News Directory. Available online: http://news.newsdirectory1.com/clubsport-starts-at-school/ (accessed on 12 June 2015).

85. Jeon, J.; Casper, J. Psychological antecedents of youth versus adult participation: An examination based on the Sport Commitment Model. J. Amat. Sport 2016, 2, 103-125. [CrossRef]

(C) 2018 by the authors. Licensee MDPI, Basel, Switzerland. This article is an open access article distributed under the terms and conditions of the Creative Commons Attribution (CC BY) license (http:/ / creativecommons.org/licenses/by/4.0/). 